\title{
FINITE ELEMENT MODELLING OF SLIPAGE BETWEEN FRP REBAR AND CONCRETE IN PULL-OUT TEST
}

\author{
Pavel Akishin ${ }^{1}$, Andrejs Kovalovs ${ }^{2}$, Vladimir Kulakov ${ }^{3}$, Alexander Arnautov ${ }^{4}$ \\ ${ }^{1,2}$ Institute of Materials and Structures, Faculty of Building and Civil Engineering, Riga Technical University, \\ Azenes Str. 16/20, LV-1048 Riga, Latvia \\ 3,4Institute of Polymer Mechanics, University of Latvia, Aizkraukles Str. 23, LV-1006 Riga, Latvia
}

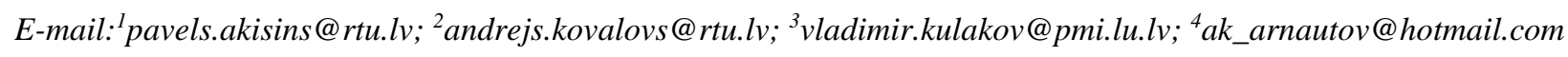

\begin{abstract}
The paper presents numerical results of direct pull-out test of glass fiber-reinforced polymer (GFRP) rebars embedded in concrete. Rebars of three different cross-sections are considered: circular without longitudinal ribs and with two and four ribs. The design analyses of the rebar configurations embedded in concrete are investigated by the 3D finite element method (FEM), which takes into account the non-linearity using ANSYS software. The results of the numerical model with two ribs were compared with the experimental results. Then, the effect of different rebar geometries to the load-slip pull-out curves was studied. It is concluded that the influence of rib height and width on the pull-out load in the rebar with 4 ribs is much higher than in the one with 2 ribs.
\end{abstract}

Keywords: glass fiber-reinforced polymer (GFRP), rebar, finite element modelling, pull-out test, load-slip behaviour, ANSYS.

\section{Introduction}

Fibre reinforced polymer (FRP) bars have become commercially available as reinforcement for concrete over the last decades. These rebars have several important advantages over conventional reinforcing steel, namely, high tensile strength, light weight, non-corrosiveness, anti-fatigue, non-magnetic, electrical insulation, small creep deformation and specific gravity. All these advantages are the main reasons of their incorporation into the civil engineering structures (Barboni et al. 1997, Benmokrane et al. 1995, Emmons et al. 1998, Midwater et al. 1997, Nanni et al. 1995, Bakis et al. 1998).

The FRP rebars are generally made of glass, carbon and aramid fiber reinforced composites can be readily formed into complex shapes through the pultrusion manufacturing process (Wallenberger et al. 2001, Walsh, 2001).

The most common manufacturing process is the pultrusion process, when the longitudinal fibers are drawn through a resin bath and then passed through a die, which gives the rebar of a final shape.

Additional techniques are required to improve the bond between the rebar and the surrounding concrete. Several techniques can be used, including surface deformations, sand coating, over-moulding a new surface on the bar or a combination of the techniques. Many researchers have brought up various formulae to estimate the bond strength of deformed composite reinforcement and studied experimentally and numerically the use of composite rebars as reinforcement in the concrete structures.

The mechanics of stress transfer by bond between FRP rebars and concrete was investigated by many authors. From the experimental results it may be concluded that the bonding of the FRP to concrete depends on the following factors: chemical bond, friction due to surface roughness of FRP rods, mechanical interlock of the FRP rods against the concrete, and induced interfacial pressure due to temperature change and concrete shrinkage during curing.
It was concluded that the pullout mechanism of many existing types of FRP reinforcement differed from that of deformed steel bars and was dependent on even more parameters. This conclusion was also reported in (Chaallal et al. 1993, Tepfers 2006). For rebars with a smooth surface, the effect of concrete mechanical properties appeared to be negligible and therefore the bond behaviour was solely dependent on the type of fibres and matrix (Nanni et al. 1995). However, for rebars with an indented and deformed surface, a strong dependence of bond strength on the confinement pressure was reported in (Malvar 1994).

Recent studies have shown that, generally, the bond between the concrete and smooth FRP rods is affected by the non-isotropic mechanical properties of the FRPs. The mechanical properties in the longitudinal direction are controlled by the fibres, but the stiffness and strength in the transversal direction depend on the resin matrix, low elastic modulus of which can reduce the bond strength (Al-Zahrani et al. 1995). Moreover, the relative smoothness of FRP rods in the longitudinal direction compared to steel reinforcing bars can also reduce friction and thus the bond strength with concrete.

Hao et al. (2007) tested 105 pull-out specimens to investigate the effect of different rib geometries on bond strength of glass fiber reinforced polymer (GFRP) rebars embedded in concrete. The experimental and theoretical results indicated that the bond strength of GFRP rebars was about $13-35 \%$ lower than that of the steel rebars. The bond strength and bond-slip behavior of the specially machined rebars varied with the rebar type, rebar diameter, rebar surface texture, rib height, rib spacing and rib width. Using these results, the design recommendations were made concerning optimum rib geometries of GFRP ribbed rebars with superior bondslip characteristics, which concluded that the optimal rib spacing of ribbed rebars is the same as the rebar diameter, and that the optimal rib height is $6 \%$ of the rebar diameter. 
Baena et al. (2009) tested 88 pull-out specimens that were prepared according to ACI 440.3R-04 and CSA S806-02 standards. Rebars (reinforcing bars) made of carbon- and glass-fibre reinforced polymers (CFRP and GFRP), as well as steel rebars with a constant embedment length of five times the rebar diameter were used. The influence of the rebar surface, rebar diameter and concrete strength on the bond-slip curves obtained is analyzed. The experimental results confirm the tendency of rebars with larger diameters to have lower bond strength. The slip values obtained for GFRP are greater than those for CFRP bars.

The application of finite element method (FEM) allows taking into consideration the specific needs like plasticity, contact, interlock and, etc. This is the main reason why FEM was applied to bond modelling by several researchers.

The finite element research of composite rebars of different shape has been proposed by (Kadioglu, 2005). Specifically, four different composite rebar configurations under axial, bending and torsional loadings are investigated using the 3D finite element analysis. The composite rebar configurations investigated include square rebar, circular rebar with ribs, and ribs oriented at an offset angle along the length of the rebar. The results of interfacial stresses obtained are presented and compared among various rebar configurations under axial, bending and torsional loadings. The idea of using ribs is to improve the bond characteristics with the surrounding concrete. The results presented in this research illustrate that various design features added to the circular composite rebar may provide good bonding characteristics and can be used in reinforced concrete structures.

Two Finite Element packages (ANSYS and ABAQUS) were used to model the bond interaction of FRP reinforcing bars in cubes and beams (Achillides et al. 2006). The main purpose of this work is to develop additional understanding of how FRP bars "cooperate" with concrete to sustain the pull-out load. Two modeling approaches were presented. In the first approach, a spring describing the behaviour of short embedment lengths in pull-out tests was used for predicting the behaviour of longer embedment lengths. In the second approach, spring characteristics obtained from an experimentally determined bond stress versus anchorage length envelope are used in FE modeling of beams. Both approaches showed good agreement between analytical and experimental results.

S. Khalfallah and M. Ouchenane (2007) presented the results of subtask dealing with the bond behaviour study of the reinforcement systems under monotonic loading pull-out tests. This numerical method is based on the slip and the bond stress distributions through the anchored length of the bar in the concrete block. The work refers, especially to the implementation of reinforcing bars and bond-slip models between steel and concrete in the developed finite element program.

Al-Zuhaiti et al. (2013) analyzed bond-slip behavior of the simple pullout concrete cylinder specimen reinforced by a single steel bar. Three-dimension nonlinear finite element model using ANSYS program was employed to study the behavior of bond between concrete and plain steel reinforcement. Material nonlinearity due to cracking and/or crushing of concrete, and yielding of the steel reinforcing bar were taken into consideration during the analysis. The accuracy of this model is investigated by comparing the finite element numerical behavior with that predicted from experimental results of three pullout specimens. The influence of bar diameter and chemical adhesion was studied.

The objective of this study is to investigate and compare the load-slip curve between GFRP rebars with different cross-sectional geometry. The influence of rib geometry on the pull-out load is presented to illustrate the effectiveness of composite rebar configurations. The result of the numerical model with two ribs was compared with the experimental results. The ANSYS finite element program was used in this study to simulate the pull-out test.

\section{Material and configuration}

The direct pull-out test is a commonly used test method for determining the bond strength of FRP rebar in concrete. Usually the FRP rebar is embedded through a cylindrical concrete specimen and is pulled from one end of the rebar. The bond strength of the FRP to concrete is determined from the force applied to the FRP divided by the interfacial contact area of the FRP bonded region.

$$
\tau=\frac{F}{\pi d l_{b}},
$$

where $F$ is the applied pull-out load, $d$ is the diameter of rebar, $l_{b}$ is the bonded length of the rebar.

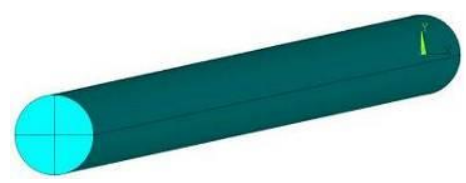

a)

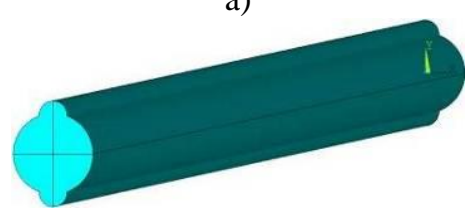

b)

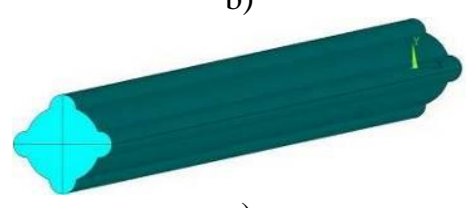

c)

Fig. 1. Shape of rebars (R1), (R2), and (R3).

Three different types of composite rebar configurations under axial loading are considered in this research. The first rebar R1 (Fig. 1a) has a standard circular crosssection that is commonly used in construction industry (Fig. 1). The second R2 and third R3 rebars have circular cross-sections with two and four longitudinal ribs respectively (Fig. 1b,c). 
Other possible configurations of this rebar type are not considered in this study. All rebars are made of FRP composite, which can be easily manufactured by means of the pultrusion process.

The modulus of elasticity for concrete was calculated using the following equation (ACI 318, 1999).

$E_{c}=4730 \sqrt{f_{c}}$,

where $f_{c}$ is ultimate compressive strength of concrete (MPa).

The ANSYS program requires the uniaxial stress-strain relationship for concrete in compression.

Next Eqs. (3) and (4) are used along with Eq. (5) to construct the uniaxial compressive stress-strain curve for concrete in this study (Kachlakev et al., 2001).

$$
\begin{aligned}
& f=\frac{E_{c} \varepsilon}{1+\left(\frac{\varepsilon}{\varepsilon_{0}}\right)^{2},} \\
& \varepsilon_{0}=\frac{2 f_{c}}{E_{c}}, \\
& E_{c}=\frac{f}{\varepsilon},
\end{aligned}
$$

where $f$ is stress at any strain $\varepsilon, \varepsilon$ is strain at stress $f, \varepsilon_{0}$ is strain at the ultimate compressive strength $f_{c}$.

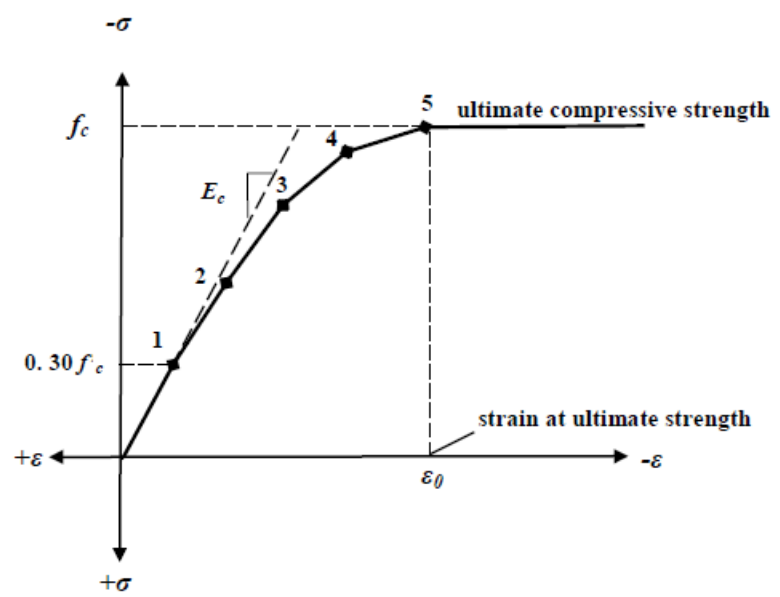

Fig. 2. Simplified compressive uniaxial stress-strain curve for concrete.

Figure 2 shows the stress-strain relationship used for this study and is based on the work done by Kachlakev et al. (2001).

The curve starts at zero stress and strain. Point No. 1, at $0.30 f_{c}$, is calculated for the stress-strain relationship of the concrete in the linear range (Eq. (5)). Points Nos. 2, 3, and 4 are obtained from Eq. (3), in which $\varepsilon_{0}$ is calculated from Eq. (4). Point No. 5 is at $\varepsilon_{0}$ and $f_{c}$. In this study, an assumption was made of perfectly plastic behavior after Point No. 5.

The value of $f_{c}$ received from experimental test.

The following properties are used in the finite element analysis for the concrete $(E=23.65 \mathrm{GPa}$ and $\mathrm{v}=0.15)$ and composite rebars UD GFRP/epoxy $\left(E_{1}=45 \mathrm{GPa} ; E_{2}=E_{3}=11 \mathrm{GPa} ; G_{12}=G_{13}=4.5 \mathrm{GPa}, v_{12}\right.$ $\left.=v_{13}=0.23\right)$. Concerning the friction coefficient between the composite and concrete, it is worth mentioning that the literature gives values for composite-concrete interfaces in the range $0.2-0.6$. In this study, a friction coefficient equal to 0.3 was identified having compared experimental and numerical results.

\section{Finite element modelling of pull-out test}

The 3D finite element models of the composite rebars and the surrounding concrete were simulated by software ANSYS14.0. The composite rebars are modelled using 3D brick elements SOLID185. The SOLID185 element type is defined by eight nodes and has three degrees of freedom (translations in $x, y, z$ directions) at each node. The SOLID 65 with 8-node was used to model the concrete. The most important aspect of this element is the treatment of nonlinear material properties. The concrete is capable of cracking (in three orthogonal directions), crushing, plastic deformation, and creep.

All calculations were made with FEM by creation of a friction interface between the composite rebar and concrete. In order to consider the effect of friction along the interfaces, Coulomb friction model was employed. In the basic Coulomb friction model, two contacting surfaces can carry shear stresses up to a certain magnitude across their interface before they start sliding relative to each other. This state is known as sticking. The Coulomb friction model for joints is defined as (ANSYS 14.0):

$\tau_{\lim }=\mu F_{n}$,

$|\tau| \leq \tau \lim$

where $\tau_{\text {lim }}$ is the limiting shear stress, $F_{n}$ is the contact pressure and $\mu$ is the current value of coefficient of friction. When $\tau$ exceeds $\tau_{\text {lim }}$, two surfaces will slide relative to each other. This state is known as sliding.

Surface-to-surface contact elements were used for the interface between the rebars and concrete. The contact surfaces of the composite rebars were meshed with CONTA 174, and the contact surfaces of the concrete cylinder were meshed with TARGE170. These finite elements join the two contact surfaces allowing them to slide relative to each other. 


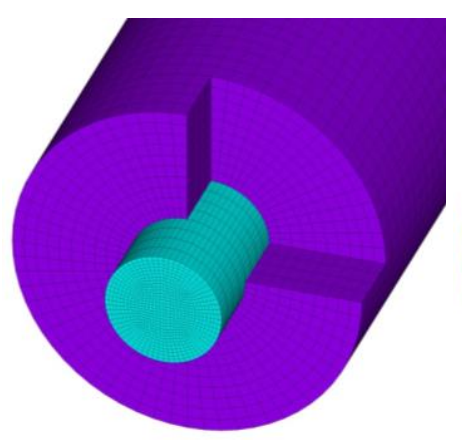

a)

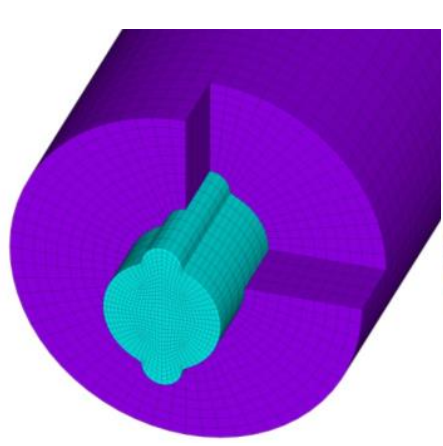

b)

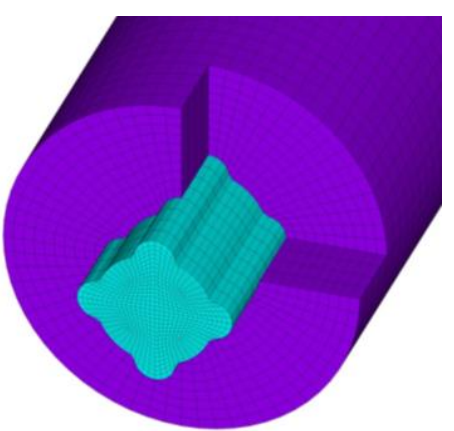

c)

Fig. 3. Fragments of finite element models for composite rebars R1 (a), R2 (b) and R3 (c).

The loading and boundary conditions were also the same as in the mechanical tests. The boundary conditions for the model are applied by fixing the nodes at the top cylinder surface in three directions. Uniaxial loading was carried out by axial displacement to the loaded end of composite rebar with ribs.

Fragments of FEM models are shown in Figure 3.

Due to the geometrical symmetry of the configurations considered, one quarter of their volume was modelled. This approach reduces computational time and computer disk space requirements significantly.

The solution was done with the assumption of small deformations.

In the beginning, it is necessary to conduct the convergence tests for the finite element model developed and validate the correctness of FEM discretization for the next calculation work. Convergence of the FEM results was examined for several models with different mesh sizes and by comparing the resulting pull-out forces. Based on these results, the appropriate mesh with brick finite elements was chosen as a primary one for the FEM models.

Before numerical study and research of GFRP rebars, the finite element analysis of rebars with two ribs was compared with the experimental results for verification. As a result, the corrected finite element model was developed.

The experimental and finite element results and discussion are presented in the next two sections.

\section{Experimental testing}

For the experimental determination of the load-slip relationship between composite rebar and concrete, pullout specimens of GFRP rebar with two ribs was used.

The cross-sectional geometry of pull-out cylinder specimen (R2) with two ribs is shown in Figure 4.

Composite rebar embedded in a cylindrical concrete block: $D=200 \mathrm{~mm}$ (diameter) and $L=150 \mathrm{~mm}$ (length). The height of rib $(h)$ is $2 \mathrm{~mm}$, width of rib $(w)$ is $2.5 \mathrm{~mm}$, diameter of rebar $(d)$ is $13 \mathrm{~mm}$ and length of composite rebar $(l)$ is $250 \mathrm{~mm}$. The bonded length $\left(l_{b}\right)$ was taken $140 \mathrm{~mm}$. The length of the deformed rebars on the loaded end was $85 \mathrm{~mm}$, in order to satisfy the load requirements of pull-out test. Length on the free end is $15 \mathrm{~mm}$.

Contact between the concrete and the rebar along the embedded length is broken using soft plastic tube to equalize the stress from the loading plate on the loaded end side and minimize the stress concentrations at the entry into the bonded length.

The experimental test machine with pullout specimen is shown in Figure 5. The GFRP was loaded at the constant rate of $2 \mathrm{~mm} / \mathrm{min}$. Figure 6 shows the comparison between the experimental and finite element results of load-slip relationship. Since the interface properties were unknown, the frictional properties and concrete shrinkage during curing were changed to obtain a better fit between numerical result and experimental data.
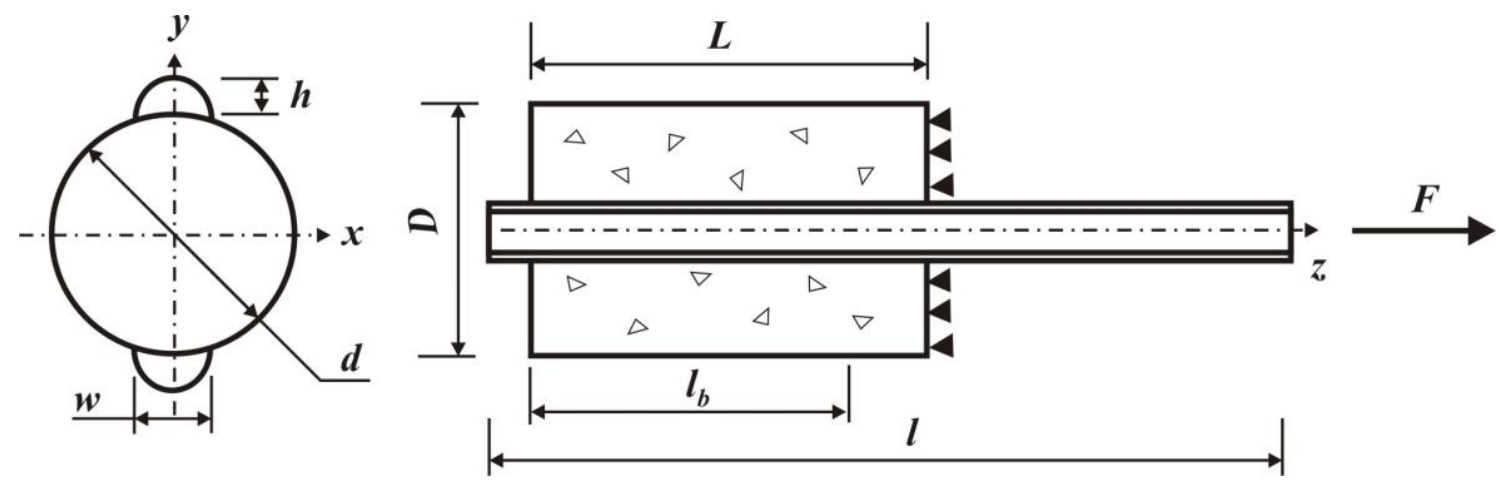

Fig. 4. Cross-sectional geometry of pullout specimen with composite rebar R2. 


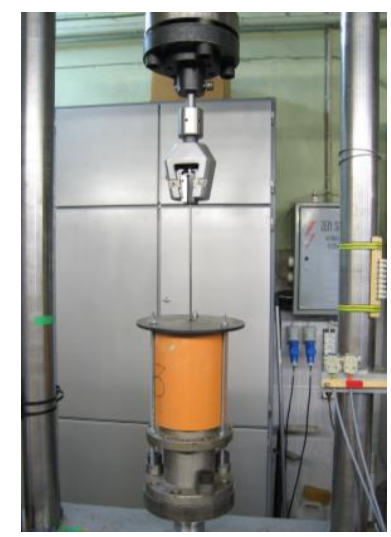

Fig. 5. Setup of pullout test.

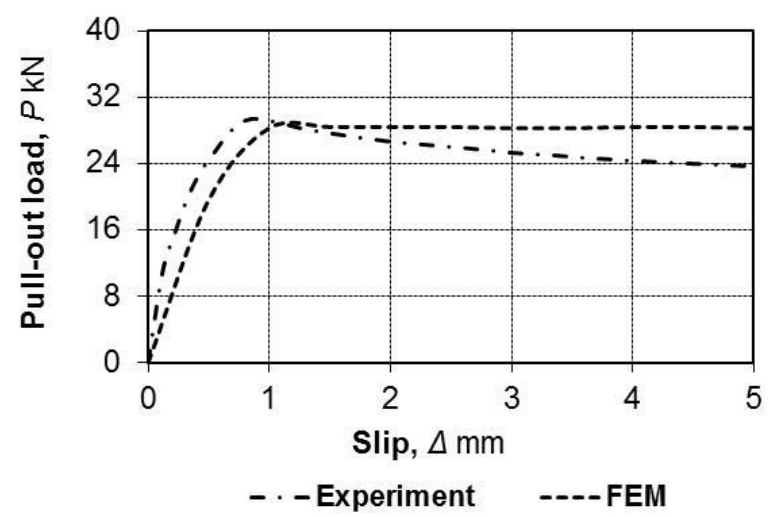

Fig. 6. Comparison of the load-slip curves obtained in 3D finite analysis and experiment.

Loading were continued until concrete split with slippage $5 \mathrm{~mm}$ at the loaded end.

In general the load-slip relationship for the GFRP rebar from the finite element analysis agrees quite well with the experimental data. The finite element load-slip relationship in the linear range is different from the experimental result. There are several effects that may cause the higher stiffness in the finite element models which is based on the work done by Kachlakev et al. (2001).

Firstly, all the microcracks in the concrete could be induced by shrinkage of the concrete and slipping of GFRP rebar during experiment. Secondly, the microcracks change the stiffness of the tested concrete specimen, but these facts are not accounted for in the finite element model, where perfect bond between the concrete and GFRP rebar is assumed. It seems that this assumption might be quite approximate one.

\section{Numerical results of pull-out load slip behaviour}

In this section the effect of different rib geometries to the maximal pull-out load is presented. Comparison of results showed that maximum pull-out load for GFRP rebar without ribs was less than for GFRP rebar with ribs.

The load-slip curves of GFRP rebars with different cross-section are shown in Figure 7. It is seen that pullout load increased with increased of number of ribs. This difference is approximately $14.4 \%$.

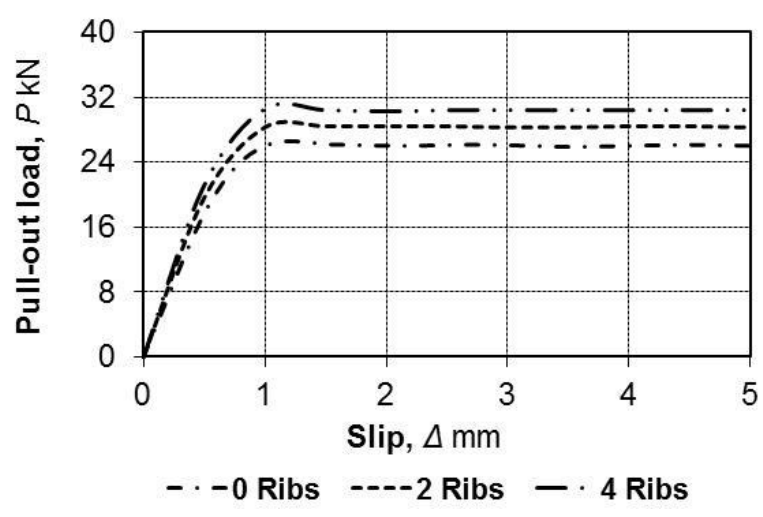

Fig. 7. Setup of pullout test.

An important geometrical parameter of the rebars is the height of the ribs. The results presented in Figure 8 illustrate the influence of the rib height on the maximal pull-out load for rebars with 2 ribs and 4 ribs under axial loading. The width of the ribs was $2.5 \mathrm{~mm}$ in all rebars studied.

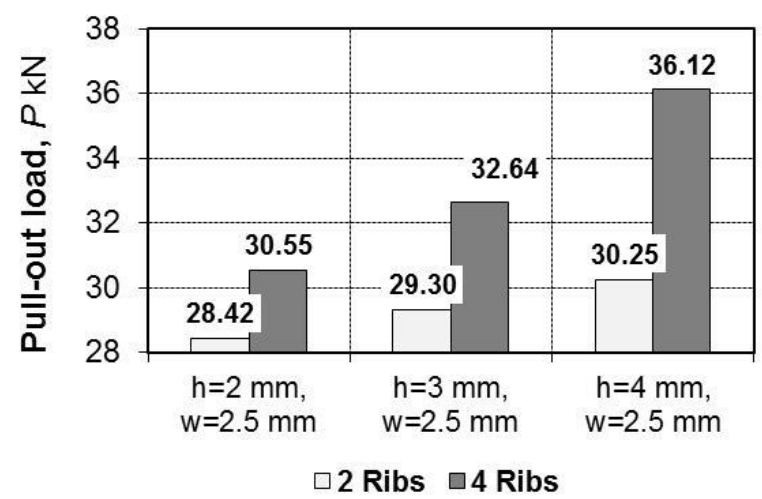

Fig. 8. Maximum pull-out load for rebars R2 and R3 via rib height.

It is seen that the pull-out load for the rebar with 4 ribs is much higher than for the one with 2 ribs. When the rib height increased from 2 to $4 \mathrm{~mm}$, the pull-out load increased, and the difference is approximately $7 \%$ for rebar with two ribs and $15.4 \%$ for rebar with four ribs.

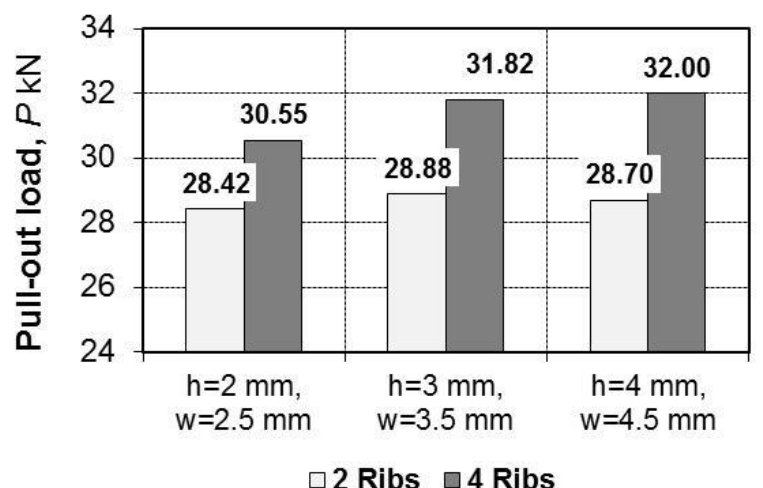

Fig. 9. Maximum pull-out load for rebars R2 and R3 via rib height and width.

The next step of FEM calculations was concerned with an estimation of the pull-out load in the case of 
simultaneous variation of the rib height and width. The maximum pull-out loads calculated for rebars with 2 and 4 ribs under axial loading are shown in Figure 9.

With the increase of width ribs, the rib heights increased respectively. Considering the effect of the difference in rib height and width, the effect of rebar with 2 ribs on pull-out load was negligible. Depending on the rib height and width for the rebar with 4 ribs, this difference is $11.2 \%$.

\section{Conclusions}

In this investigation, experimental results of the pullout test and modeling were compared. The numerical pull-out analyses for the composite rebars embedded in concrete are performed by the 3D FEM using ANSYS software.

After comparison of the test results and the numerical result the 3D FEM model with two ribs was verified and the rebars of circular cross-section with two and four longitudinal ribs, as well without ribs were studied. The effect of different rib geometries on the maximal pull-out load was also investigated.

Based on the results of the preliminary parametric analysis of slippage between GFRP rebars and concrete under uniaxial tension, the following conclusions can be made.

- The number of the longitudinal ribs influences significantly the pull-out load between composite rebars and concrete.

- In the case of rebars with 2 longitudinal ribs, pullout load is $7 \%$ less than that for rebars with 4 ribs ( $h=2 \mathrm{~mm}, w=2.5 \mathrm{~mm}$ ).

- The height of the ribs has more influence on the pull-out load for rebar with 4 ribs (15.4\%).

- It was shown that increase of height and width was negligible for the rebar with 2 ribs.

\section{References}

ACI 318-99, American Concrete Institute, Building Code Requirements for Reinforced Concrete, American Concrete Institute, Farmington Hills, Michigan, 1999

Achillides, Z.; Pilakoutas, P., 2006. FE modelling of bond interaction of FRP bars to concrete. Structural Concrete, 7(1), pp.7-16. http://dx.doi.org/10.1680/stco.2006.7.1.7

Al-Zahrani, M. M.; Al-Dulaijan, S. H., 1995. Annotated bibliography of bond behavior in FRP/concrete systems. Report CMTC-9501. Composite Manufacturing Technology Centre, $72 \mathrm{p}$.

Al-Zuhairi, H.A.; Al-Fatlawi, W. D., 2013. Numerical prediction of bond slip behaviour in simple pull-out concrete specimens. Journal of Engineering, 19(1), pp.72.

ANSYS, “ANSYS Help”, Release 12.1, Copyright 2009.

Baena, M.; Torres, L.; Turon, A.; Baris, C., 2009. Experimental study of bond behaviour between concrete and FRP bars using a pull-out test. Composites Part B, 40, pp. 784-797 http://dx.doi.org/10.1016/j.compositesb.2009.07.003

Bakis, C.E.; Uppuluri, V.S.; Nanni, A.; Boothby, T.E., 1998. Analysis of bonding mechanisms of smooth and lugged FRP rods embedded in concrete. Composite Science and Technology, 58, pp. 1307-19.
http://dx.doi.org/10.1016/S0266-3538(98)00016-5

Barboni, M.; Benedetti, A.; Nanni, A., 1997. Carbon FRP strengthening of doubly curved precast PC shell. Journal of Composite Construction, 1, pp.168-74. http://dx.doi.org/10.1061/(ASCE)1090-0268(1997)1:4(168)

Benmokrane, B.; Chaallal, O.; Masmoudi, R., 1995. Glass fibre reinforced plastic (GFRP) rebars for concrete structures. Construction and Building Materials, 9(6), pp. 353-364. http://dx.doi.org/10.1016/0950-0618(95)00048-8

Chaallal, O.; Benmokrane, B., 1993. Pullout and bond of glassfibre rods embedded in concrete and cement grout. Material Structure, 26(3), pp. 165-75. http://dx.doi.org/10.1007/BF02472934

Kachlakev, D.; Miller, T., 2001. Finite element modeling of reinforced concrete structures strengthened with FRP laminates. Research Report, SPR 316, Oregon Department of Transportation Research Group, 2001.

Emmons, P.H.; Vaysburd, A.M.; Thomas J., 1998. Strengthening concrete structures. Part II. Concrete International, 20(3), pp. 56-60.

Fethi, K.; Ramana, M.; Pidaparti., 2005. Composite rebars shape effect in reinforced structures. Composite Structures 67(1), pp. 19-26.

http://dx.doi.org/10.1016/j.compstruct.2004.01.006

Khalfallah, S.; Ouchenane, M., 2007. A numerical simulation of bond for pull-out tests: the direct problem. Asian Journal of Civil Engineering, 8(5), pp. 491-505.

Malvar, L.J., 1994. Bond stress-slip characteristics of FRP rebars. Technical Report TR-2013-SHR, Naval Facilities Engineering Service Center, Port Hueneme, California, CA 93043-4328, pp. 45.

Midwater, K.R., 1997. Plate bonding carbon fiber and steel plates. Construction Repair, 11(5), pp.8.

Nanni, A., 1995. Concrete repair with externally bonded FRP reinforcement: examples from Japan. Concrete International, 17 (22), pp.6.

Nanni, A.; Al-Zaharani, M.M.; Al-Dulaijan, S.U.; Bakis, C.E.; Boothby, T.E., 1995. Bond of reinforcement to concrete experimental results. In Proc of second international RILEM symposium (FRPRCS-2), 23-25 August, 1995, Ghent, Belgium, pp.114-17.

Tepfers, R., 2006. Bond clause proposal for FRP-bars/rods in concrete based on CEB/FIP Model Code 90. Part 1: design bond stress for FRP reinforcing bars. Structural Concrete, 7(2), 47, pp.55.

Hao, Q.; Wang, Y.; Zhang, Z.; Ou, J., 2007. Bond strength improvement of GFRP rebars with different rib geometries. Journal of Zhejiang University, 8(9), pp. 1356-1365. http://dx.doi.org/10.1631/jzus.2007.A1356

Wallenberger, F. T., Watson, J. C.; Hong, L., 2001. Glass Fibers. ASM Handbook-Composites. ASM International 21, pp. 1201.

Walsh, P. J., 2001. Carbon Fibres, ASM Handbook-Composites. ASM International, 21, pp. 1201.

\section{Acknowledgements}

This work has been supported by ERAF project No/ 2010/0296/2dp/2.1.1.1.0/10/APIA/VIAA/049 